\title{
HUBUNGAN KOMUNIKASI DAN REWARD DENGAN PENERAPAN PATIENT CENTERED CARE DI INSTALASI RAWAT INAP
}

\author{
Fitriya Handayani ${ }^{1}$ \\ 1, Jurusan Keperawatan Universitas Borneo Tarakan \\ *Email: fitriyahalik@gmail.com
}

\begin{abstract}
Abstrak
Penggunaan patient centered care yang baik dapat meningkatkan status kesehatan dan meningkatkan efisiensi dalam pemberian pelayanan keperawatan, tetapi penggunaan patient centered care masih mengalami banyak kendala dalam pelaksanaannya. Tujuan Penelitian : Diketahuinya hubungan komunikasi dan reward dengan penerapan patient centered care di Instalasi Rawat Inap RSUD Dr. M.M. Dunda Limboto. Metode penelitian : Penelitian ini merupakan penelitian kuantitatif dengan metode korelasi melalui pendekatan cross sectional. Sampel dalam penelitian ini berjumlah 70 responden, tekhnik pengambilan sampel menggunakan total sampling. Analisa data menggunakan analisis univariat dan bivariat. Hasil Penelitian : terdapat hubungan komunikasi dan reward dengan patient centered care di Instalasi Rawat Inap RSUD Dr. M.M. Dunda Limboto. Saran : Diharapkan pihak manajemen rumah sakit untuk mengadakan pelatihan patient centered care dan meningkatkan reward serta diharapkan perawat untuk meningkatkan komunikasi yang baik guna meningkatkan mutu pelayanan di umah sakit.
\end{abstract}

Kata Kunci : Komunikasi, Reward dan Pelayanan yang berpusat pada pasien

\begin{abstract}
Relationship between Communication and Reward with the Application of Patient Centered Carein In patient Installation. The use of patient centered care that can improve health status and increase efficiency in the delivery of nursing services, but the use of patient centered care still has many obstacles in its implementation. Aims: Knowing the relationship of communication and reward with the application of patient centered care at the Inpatient Installation of Dr. M.M. Dunda Limboto Hospital. Method: This research is a quantitative study with a correlation method through a cross sectional approach, sample in this study were 45 respondents the sampling technique used total sampling. Data analysis using univariate analysis. Result: there is a relationship between communication and reward with patient centered care at the Inpatient Installation of Dr. M.M. Dunda Limboto Hospital Suggestion : $t$ is expected that the hospital management to conduct patient centered care training and improve rewards and nurses are expected to improve good communication in order to improve the quality of services in hospitals.
\end{abstract}

Keywords: Communication, Reward and Patient Centered Care. 


\section{Pendahuluan}

Perkembangan dalam dunia usaha saat ini di Indonesia termasuk usaha di bidang kesehatan yaitu rumah sakit yang semakin cepat dan pesat berakibat juga pada perubahan budaya. Rumah sakit merupakan salah satu organisasi pelayanan dibidang kesehatan yang memiliki budaya organisasi yang tercermin dalam visi, misi, dan tujuan yang ingin dicapai. Tujuan pelayanan kesehatan di rumah sakit yakni memberikan pelayanan sesuai dengan standar pelayanan kesehatan dan berkualitas. Kualitas pelayanan sangat ditunjang oleh perilaku atau kinerja pemberi pelayanan yang salah satunya adalah perawat (Pohan, 2007).

Untuk menjaga kualitas pelayanan kesehatan di Indonesia seperti yang tertulis pada Undang-Undang (UU) Kesehatan Nomor 36 / 2009 bahwa pemerintah diberikan tanggung jawab untuk menyediakan pelayanan kesehatan yang aman, bermutu, dan terjangkau bagi seluruh masyarakat. Begitu pula dengan UU Rumah Sakit Nomor 44/2009 yang secara tegas menyatakan bahwa mutu pelayanan dan keselamatan pasien merupakan dasar dan tujuan dalam penyelenggaraan rumah sakit.
Peraturan-peraturan ini merupakan gambaran pentingnya sebuah pelayanan kesehatanan yang aman dan berkualitas yang harus disiapkan sebagai bagian dari sistem kesehatan.

Pelayanan yang berpusat pada pasien (patient centeredness) saat ini diterima secara luas sebagai inti utama pelayanan kesehatan (AF4Q, 2012). Hal ini menyebabkan rumah sakit secara terus menerus berusaha meningkatkan kualitas pelayanan khususnya pelayanan keperawatan. Keperawatan adalah kelompok profesi terbesar dan berperan vital dalam sistem tersebut yang menyebabkan perawat memiliki kontribusi kinerja yang penting dalam penentuan kualitas sebuah rumah sakit (Marquis \& Huston, 2010).

Konsep patient centered care (pelayanan berpusat kepada pasien) sudah diterapkan banyak rumah sakit di negara maju. Konsep patient centered care sebagai filosofi dalam memberikan pelayanan kedokteran merupakan pendekatan yang bisa dilakukan karena dalam pendekatan ini terjadi hubungan timbal balik antara penyedia pelayanan dan pasien sehingga akan meminimalkan konflik yang selama ini timbul sebagai akibat kurangnya komunikasi dan informasi. Patient centered care 
dapat dipraktekkan dalam segala tahapan usia dan berbagai macam latar belakang (Kusumaningrum, 2009).

Salah satu dimensi yang sangat mempengaruhi pelayanan yang berpusat pada pasien yaitu komunikasi. Komunikasi adalah proses penyampaian dan pertukaran informasi dari pengirim kepada penerima, baik secara lisan, tertulis maupun menggunakan alat komunikasi. Komunikasi memiliki peranan yang penting dalam membentuk organisasi yang efektif dan efisien. Informasi yang akurat, jujur, mengenai suatu pekerjaan selama proses perekrutan dan seleksi, memberikan asumsi dan nilai bagi karyawan sehingga berpengaruh terhadap motivasi dan kinerja karyawan (Robbins \& Judge, 2008).

RSUD. Dr. M.M Dunda Limboto merupakan rumah sakit tipe $\mathrm{B}$ dan merupakan rumah Sakit rujukan di kabupaten Gorontalo dengan visi yaitu Menjadi Rumah Sakit Terbaik di Provinsi Gorontalo. Misi rumah sakit yaitu: (1) Memberikan pelayanan kesehatan yang profesional,bermutu, tepat waktu dan terjangkau oleh seluruh lapisan masyarakat, (2) meningkatkan dan mengembangkan sumber daya manusia melalui pendidikan dan pelatihan, (3) meningkatkan pendapatan rumah sakit dan mandiri dalam pendanaan, (4) meningkatkan kesejahteran karyawan, mengembangkan penelitian dan pengembangan dalam teknologi kesehatan (Profil RSUD DR. M. M. Dunda Limboto, 2017).

Saat ini di RSUD Dr. M.M Dunda Limboto masih dalam tahap perubahan ke arah pelayanan yang berpusat pada pasien yang mana berhubung rumah sakit dalam proses persiapan akreditasi serta dalam proses peningkatan kualitas pelayanan apalagi jika dilihat terjadi penurunan pencapaian BOR. Pelayanan yang berpusat pada pasien juga merupakan suatu bentuk pelayanan kesehatan yang menciptakan hubungan kerjasama yang baik diantara praktisi kesehatan, pasien, dan keluarganya. Oleh karena itu mengingat perawat merupakan pemberi pelayanan yang terbanyak di rumah sakit dan memegang peranan penting dalam memberikan pelayanan kesehatan, maka dalam penelitian ini perawat akan menjadi pusat perhatian dalam pelaksanaan budaya organisasi dan perubahannya kearah pelayanan yang berpusat pada pasien. 
Menurut wawancara awal dari 3 orang kepala ruangan di ruang rawat inap RSUD Dr. M. M. Dunda Limboto menyatakan bahwa untuk merubah budaya yang berpusat pada pasien masih menemukan banyak kendala terutama pada komunikasi dan pengambilan resiko. Terkadang perawat jarang memberi informasi kepada pasien dan keluarga serta kurang memperhatikan pasien.

Begitu halnya dengan hasil wawancara awal dengan 8 orang perawat pelaksana yang berada di ruang perawatan berbeda bahwa dalam pemberian pelayanan yang berpusat masih sering mengalami kendala selain dari komunikasi antara perawat dengan pasien dan keluarga juga antara perawat dengan praktisi kesehatan lainnya seperti dokter, ahli gizi, apoteker, dan fisioterapis. Selain itu juga terdapat kendala dalam kerjasama yang mana kurangnya kerjasama dari pasien dan keluarganya dalam pemberian informasi kepada perawat begitupun sebaliknya.

Pelayanan yang berpusat pada pasien harus ditanamkan dan menjadi budaya yang melekat pada jiwa perawat sehingga tiap tindakan dan informasi yang diberikan berguna bagi pasien dan keluarga serta tidak memihak kepada pasien dan keluarga. Pasien dan keluarga menerima informasi setiap waktu, lengkap, akurat agar dapat berpartisipasi dalam pengobatan dan pengambilan keputusan. Kerjasama antara tim kesehatan juga harus di tingkatkan agar pemberian pelayanan lebih meningkat dan berkualitas.

Fenomena inilah yang membuat peneliti tertarik untuk meneliti tentang Hubungan komunikasi dan Reward yang mempengaruhi perubahan budaya pelayanan yang berpusat pada pasien di RSUD Dr. M. M. Dunda Limboto.

\section{Metode}

Penelitian ini merupakan penelitian survei analitik dengan metode “cross sectional”. Subjek yang diteliti yaitu perawat di 6 ruang rawat inap RSUD Dr.M.M. Dunda Limboto. Metode ini dimulai dengan mengumpulkan data, menganalisis data dan menginterprestasikan (Notoatmodjo, 2012).

Pengambilan sampel menggunakan total sampling yang dilakukan di 6 ruang rawat inap RSUD Dr.M.M. Dunda Limboto berjumlah 70 responden. Penelitian ini di dilaksanakan mulai bulan Oktober 2016 s/d Januari 2017. Teknik pengumpulan 
data dengan data primer dengan melakukan wawancara langsung menggunakan kuesioner dan data sekunder didapat dari data profil Rumah Sakit dan Rekam Medik. Pengolahan data yang digunakan teknik analisis Univariat dan Bivariat dengan menggunakan uji statistik Chi-square.
Analisis univariat terdiri dari komunikasi, reward dan patient centered care, analisis bivariat untuk mengetahui hubungan komunikasi dan reward dengan penerapan patient centered care di Instalasi Rawat Inap RSUD Dr. M. M. Dunda Limboto. Analisis univariat dan bivariat tersebut dapat dilihat dari tabel berikut:

\section{Hasil dan Pembahasan}

\section{Tabel 1}

Distribusi Frekuensi Komunikasi dan Reward Dengan Patient Centered Care di Instalasi Rawat Inap $(n=70)$

\begin{tabular}{llcl}
\hline No & Karakteristik & $\boldsymbol{F}$ & \% \\
\hline 1 & Komunikasi & & \\
& 1. Baik & 35 & 50,0 \\
& 2. Kurang Baik & 35 & 50,0 \\
\hline 2 & Reward & & \\
& 1. Baik & 26 & 37.1 \\
& 2. Kurang & 44 & 62.9 \\
\hline 3 & Patien Centered Care & & \\
& 1. Baik & 29 & 41,4 \\
& 2. Kurang & 41 & 58,6 \\
\hline
\end{tabular}

Berdasarkan tabel 1 diatas diperoleh hasil distribusi frekuensi dari 70 responden, variabel komunikasi dengan kategori baik sebanyak 35 (50\%), reward terbanyak kategori kurang $(62,9 \%)$ dan penerapan patient centered care terbanyak kategori kurang sebanyak $41(58,6 \%)$.

Tabel 2

Hubungan Komunikasi dan Reward Dengan Patient Centered Care di Instalasi Rawat Inap

\begin{tabular}{|c|c|c|c|c|c|c|c|c|}
\hline \multirow{3}{*}{ Variabel } & \multirow{3}{*}{ Kategori } & \multicolumn{4}{|c|}{ Patient Centered Care } & \multirow{2}{*}{\multicolumn{2}{|c|}{ Jumlah }} & \multirow{3}{*}{ P value } \\
\hline & & \multicolumn{2}{|c|}{ Kurang } & \multicolumn{2}{|c|}{ Baik } & & & \\
\hline & & $\mathrm{n}$ & $\%$ & $\mathrm{~N}$ & $\%$ & $\mathbf{N}$ & $\%$ & \\
\hline \multirow{2}{*}{ Komunikasi } & Kurang & 26 & 37.1 & 9 & 12.9 & 35 & 50.0 & \multirow{2}{*}{0,015} \\
\hline & Baik & 15 & 21.4 & 20 & 28.6 & 35 & 50.0 & \\
\hline \multirow{2}{*}{ Reward } & Kurang & 32 & 45.7 & 12 & 17.1 & 44 & 62.9 & \multirow{2}{*}{0.004} \\
\hline & Baik & 9 & 12.9 & 17 & 24.3 & 26 & 37.1 & \\
\hline
\end{tabular}


Berdasarkan tabel 2 Variabel Komunikasi menunjukkan perawat pelaksana yang mempersepsikan komunikasi baik dengan pelayanan yang berpusat pada pasien baik sebanyak $(28,6 \%)$. Hasil uji statistik menunjukkan ada hubungan yang bermakna antara komunikasi dengan pelayanan yang berpusat pada pasien $(\mathrm{p}=0,015)$.

Hasil analisis hubungan reward dengan pelayanan yang berpusat pada pasien menunjukkan perawat yang mempersepsikan reward baik dengan pelayanan yang berpusat pada pasien baik sebanyak (24,3\%). Sedangkan perawat pelaksana yang mempersepsikan pengambilan risiko kurang dengan pelayanan yang berpusat baik sebanyak $(17,1 \%)$. Hasil analisis statistik menunjukkan ada hubungan yang bermakna antara reward dengan pelayanan yang berpusat pada pasien $(\mathrm{p}=$ $0,004)$.

\section{Pembahasan}

1. Hubungan Komunikasi Dengan Patient Client Centered Care di Instalasi Rawat Inap RSUD Dr.

\section{M.M. Dunda Limboto.}

Berdasarkan hasil penelitian didapatkan bahwa komunikasi yang digunakan setengahnya (50\%) adalah baik. Hasil penelitian ini jauh beda dengan penelitian Qomariah \& Lidiyah (2015) di Rumah Sakit Muhammadiyah Gresik yang didapatkan sebanyak (67\%) responden menggunakan komunikasi yang baik.

Hasil uji statistik menunjukkan ada hubungan yang bermakna antara komunikasi dengan pelayanan yang berpusat pada pasien $(\mathrm{p}=0,015)$. Hasil penelitian ini didukung oleh penelitian Sulistyo (2009) yang didapatkan hasil terdapat pengaruh yang signifikan antara komunikasi organisasional dengan kinerja karyawan.

Komunikasi merupakan proses penyampaian dan pertukaran informasi dari pengirim kepada penerima, baik secara lisan, tertulis maupun menggunakan alat komunikasi. Komunkasi memiliki perananan yang penting dalam membentuk organisasi yang efektif dan efisien. Informasi yang akurat, jujur mengenai suatu pekerjaan selama proses perekrutan dan seleksi, memberikan asumsi dan nilai bagi karyawan, sehingga 
berpengaruh terhadap motivasi dan kinerja karyawan (Robbins \& Judge, 2008).

Komunikasi merupakan kumpulan dari individu yang berinteraksi satu sama lain sehingga masalah komunikasi memegang peran sentral. Komunikasi yang baik menciptakan saling pengertian dan akan memperkuat kohesi dan tercapainya tujuan-tujuan kelompok yang berdampak pada tujuan organisasi (Sopiah, 2009).

Komunikasi yang dapat memberikan dampak terhadap pelayanan yang berpusat pada pasien yaitu memberikan informasi yang akurat, jujur, mengenai pelayanan yang berpusat pada pasien selama proses perekrutan, seleksi dan sosialisasi. Proses perekrutan, seleksi dan sosialisasi dapat memberikan asumsi dan nilai bagi perawat sehingga berdampak terhadap motivasi dan kinerja perawat dalam melakukan pelayanan yang berpusat pada pasien.

\section{Hubungan Reward Dengan Patient Client Centered Care di Instalasi Rawat Inap RSUD Dr. M.M. Dunda Limboto Tahun 2017}

Hasil analisis hubungan reward dengan pelayanan yang berpusat pada pasien menunjukkan perawat pelaksana yang mempersepsikan reward baik dengan pelayanan yang berpusat pada pasien baik sebanyak $(24,3 \%)$. Sedangkan perawat pelaksana yang mempersepsikan reward kurang dengan pelayanan yang berpusat pada pasien baik sebanyak $(17,1 \%)$. Hasil analisis statistik menunjukkan ada hubungan yang bermakna antara reward dengan pelayanan yang berpusat pada pasien $(p=0,004 \alpha=$ $0,05)$.

Perusahaan menggunakan reward sebagai suatu sistem balas jasa atas hasil kerja anggota/ karyawan. Perilaku yang diberi imbalan, dihukum, dan dibiarkan yang akan menentukan bagaimana sebuah budaya organisasi berevolusi. Perusahaan yang memiliki sistem reward yang didasarkan pada intingiable performance menciptakan budaya organisasi yang berorientasi pada karyawan atau tim. Budaya 
organisasi akan berorientasi pada hasil jika kriteria balas jasa berorientasi pada target pencapaian (Riani, 2011).

Manajemen perlu memberikan penghargaan kepada karyawan yang telah menunjukkan kerja keras untuk menyenangkan pelanggan, seperti kenaikan gaji dan promosi berdasarkan layanan pelanggan yang luarbiasa. Pendapat ini didukung oleh Muzaputri (2008) dan aminuddin (2002) menjelaskan ada hubungan antara imbalan dan kinerja perawat. Robbins \& Judge (2008) menekan-kan jika manajemen menginginkan karyawan memberikan layanan yang bagus, karyawan harus diberikan imbalan yang layak. Zaccher \& Frese (2011) menyatakan terdapat hubungan antara reward dengan kinerja karyawan.

Pemberian imbalan tidak selalu dalam bentuk uang sebab bentuk materi akan sampai pada titik jenuh. Manajer keperawatan harus memperhatikan pemberian imbalan non materil misalnya suasana kerja yang kondusif, kesempatan pengembangan kreativitas, syarat kerja yang tidak terlalu ketat, dan kondisi kerja yang lebih manusiawi. Pemberian imbalan yang lebih efektif oleh manajer akan meningkatkan produktifitas kerja karyawan (Anoraga, 1995).

Pemberian reward finansial maupun non finansial kepada perawat pelaksana masih belum dilaksanakan secara optimal. Perawat yang melakukaan pelayanan yang berpusat pada pasien dengan yang tidak memberikan pelayanan mendapatkan penghargaan yang sama baik secara finansial maupun non finansial. Hal ini dibuktikan dengan hasil analisis univariat $62,9 \%$ perawat menyatakan reward kurang.

\section{Kesimpulan}

1. Sebagian besar responden $(58,6 \%)$ menggunakan patient cnetered care yang kurang baik.

2. Setengahnya responden $(50,0 \%)$ mengatakan komunikasi yang digunakan baik.

3. Sebagian besar responden $(62,9 \%)$ mengatakan pembagian reward kurang baik.

4. Terdapat hubungan komunikasi dengan penerapan patient centered care di rumah sakit dengan nilai $p$ value $(0,015)$. 
5. Terdapat hubungan reward dengan penerapan patient centered care di

\section{Referensi}

Aligning Forces four Quality. (2012). Measuring Patient Experience. Canada: Robert Wood Jhonson Foundation. Diakses dari www.rwjf.org/files/research/74242. measuring.pt.experience.0412.pdf pada 2 Agustus 2016.

Aprianto, Brian \& Jacob, A.F. (2013). Pedoman Lengkap Profeisonal SDM Indonesia. Jakarta : PPM Management.

Departemen Kesehatan RI. (2009.) Undang-Undang Republik Indonesia Nomor 36 Tahun 2009 Tentang Kesehatan. Jakarta: Kementrian Kesehatan RI.

Kusumaningrum, Arie. (2009). Aplikasi dan Strategi Konsep Patient Centered Care Pada Hospitalisasi Anak Pra Sekolah. Fakultas Kedokteran Sriwijaya.

Marquis, B. L., \& Huston, C. J. (2010). Kepemimpinan dan manajemen keperawatan, teori dan aplikasi. Jakarta: EGC. rumah sakit dengan nilai $p$ value $(0,004)$.

Nasir.A.et al. (2011). Komunikasi dalam keperawatan. Jakarta: Salemba Medika.

Notoatmodjo, Soekidjo. (2012). Metodologi Penelitian Kesehatan. Jakarta : Rineka Cipta.

Nursalam. (2014). Manajemen Keperawatan Aplikasi dalam Praktik Keperawatan Profesional.

Pohan, I. (2007). Penjaminan Mutu Kesehatan. Jakarta: Salemba Medika

Riani, A. (2011). Budaya Organisasi. Yogyakarta: Graha Ilmu

Robbins, S \& Judge, T. (2008). Perilaku Organisasi. (Terj. D. Angelica, R. Cahyani, dan A. Rosyid) Edisi 12. Jakarta: Salemba Empat. (Buku Asli tahun 2007)

RSUD DR. M. M. Dunda Limboto (2017). Profil RSUD RSUD DR. M. M. Dunda Limboto Tahun 2017. Gorontalo.

Sopiah. (2009). Perilaku Organisasional. Yogyakarta: Andi Offset. 
Fitriya Handayani. Hubungan Komunikasi Dan Reward Dengan Penerapan Patient Centered Care Di Instalasi Rawat Inap

Sulistyo, H. (2009). Pengaruh kepemimpinan spiritual dan komunikasi organisasi terhadap kinerja karyawan. Jurnal ekonomi $\&$ bisnis (Ekobis). Volume 6

Wahyuni, yanis, E. (2013). Artikel Penelitian Hubungan Komunikasi Dokter - Pasien Terhadap Kepuasan. Jurnal Kesehatan Andalas, 2(3), 175-177.
Qomariah \& Lidiyah (2015). Hubungan faktor komunikasi dengan insiden keselamatan pasien. Journal of Ners Community, 06(November).

Zacher \& Frese. (2011). Faktor Yang Berpengaruh Terhadap Kinerja Perawat di Rumah Sakit Tingkat III 16.06.01 Ambon. Jurnal AKK, Vol 2 No 1. 